\title{
Sensory and physicochemical evolution of tropical cooked peeled shrimp inoculated by Brochothrix thermosphacta and Lactococcus piscium CNCM l-4031 during storage at $8{ }^{\circ} \mathrm{C}$
}

\author{
Papa Abdoulaye Fall ${ }^{\mathbf{a}, \mathbf{b}, \mathbf{c}}$, Marie France Pilet ${ }^{\mathbf{b}, \mathbf{c}}$, François Leduc ${ }^{\mathrm{d}}$, Mireille Cardinal ${ }^{\mathbf{a}}$, Guillaume \\ Duflos $^{\mathrm{d}}$, Camille Guérin ${ }^{\mathrm{a}}$, Jean-Jacques Joffraud ${ }^{\mathrm{a}}$ and Françoise Leroi ${ }^{\mathrm{a}, \text { * }}$
}

\author{
a Ifremer, Laboratoire de Science et Technologie de la Biomasse Marine, F-44311 Nantes, France \\ ${ }^{\mathrm{b}}$ LUNAM Université, Oniris, UMR 1014 Secalim, Nantes, F-44307, France \\ c INRA, Nantes, F-44307, France \\ ${ }^{d}$ Anses, Laboratoire des produits de la pêche, Boulogne/mer, F-62200, France
}

\author{
*: Corresponding author : Françoise Leroi, phone : +33240374172 ; fax : +33240374071 \\ email address : Francoise.leroi@ifremer.fr
}

\begin{abstract}
:
This study investigated the sensory quality and physicochemical evolution $(\mathrm{pH}$, glucose, I-lactic acid, biogenic amine, free amino-acids and volatile compounds) during storage at $8{ }^{\circ} \mathrm{C}$ of cooked peeled shrimp inoculated with the specific spoilage bacteria Brochothrix thermosphacta alone or mixed with the protective strain Lactococcus piscium CNCM I-4031. Growth of both bacteria was monitored at regular intervals during storage by microbial counts and the thermal temperature gradient gel electrophoresis (TTGE) technique. Bacterial counts showed that $L$. piscium and $B$. thermosphacta inoculated at $7 \mathrm{log} C F U / g$ and $3 \log C F U / g$ were well adapted to shrimp, reaching a maximum level of 9 log CFU/g after 4 days and 10 days respectively. In mixed culture, the growth of $B$. thermosphacta was reduced by $3.2 \pm 0.1 \mathrm{log}$ CFU/g. The TTGE technique allowed monitoring the colonisation of the strains on the shrimp matrix and confirming the dominance of $L$. piscium in mixed culture throughout the experiment. Sensory analysis confirmed that $B$. thermosphacta spoiled the product after 11 days, when its cell number attained 8 log CFU/g with the emission of strong butter/caramel off-odours. This sensory profile could be linked to the production of 2,3 butanedione, cyclopentanol, 3-methylbutanol, 3-methylbutanal, 2-methylbutanal, 4-methyl-3-chloro-3-pentanol and ethanol, which were produced in more significant quantities in the $B$. thermosphactabatch than in the batches in which the protective strain was present. On the contrary, TVBN and TMA were not suitable as quality indicators for $B$. thermosphacta spoilage activity. In the products where the protective $L$. piscium strain was present, no adverse effect on sensory quality was noted by the sensory panels. Moreover, biogenic amine assessment did not show any histamine or tyramine production by this strain, underlining its safety profile. Both strains produced lactic acid $(1850 \mathrm{mg} / \mathrm{kg}$ in L. piscium and B. thermosphacta batch on days 3 and 10 respectively; $3830 \mathrm{mg} / \mathrm{kg}$ on day 7 in mixed culture) and the $\mathrm{pH}$ decrease from $6.6 \pm 0.0$ to $5.9 \pm 0.1$ was similar in all batches. Lactic acid production or competition for free amino-acid was not involved in the inhibition mechanism; however rapid glucose consumption by $L$. piscium could partially explain the growth limitation of the spoilage micro-organism. This study demonstrated the spoilage characteristic of $B$. thermosphacta and the usefulness of $L$. piscium as a bioprotective culture for tropical cooked peeled shrimp without any adverse effect on the sensory quality of the product.
\end{abstract}




\section{Highlights}

Brochothrix thermosphacta spoiles cooked/peeled shrimp packed in modified atmosphere. Inoculating shrimp by Lactococcus piscium inhibits growth of $B$. thermosphacta. This leads to extension of the sensory shelf-life by more that 31 days. The inhibition is not due to bacteriocin, lactic acid or competition for amino acids. L Liscium has no adverse effect on shrimp quality and presents safety character.

Keywords : Biopreservation; Sensory quality; Volatile compounds; Biogenic amines; Amino-acid; TTGE 


\section{Introduction}

Seafood products permit the development of a wide range of undesirable microorganisms that include spoiling bacteria, due to their physico-chemical characteristics (neutral $\mathrm{pH}$, high content of small nitrogenous compounds) (Huis in't Veld, 1996). The growth of these unwanted bacteria leads to food spoilage which is a major economic problem. Therefore understanding bacterial mechanisms leading to sensory deterioration and developing methods to preserve seafood is obviously a priority. Ready-to-eat cooked and peeled shrimp packed under modified atmosphere is more and more popular in Europe. This product is highly perishable and shelf-life does not exceed 12 days at $4^{\circ} \mathrm{C}$ when no preservatives are applied (French company communication). The spoilage microflora of cooked shrimp has been studied recently and includes lactic acid bacteria (LAB) and the specific spoilage organism Brochothrix thermosphacta (Dalgaard et al., 2003; Jaffrès et al., 2009; Mejlholm et al., 2005; Laursen et al., 2006). As in most seafood products, microbial spoilage in shrimp often depends on the levels reached by the bacteria involved during storage. Minimising this level may help to fight against seafood product spoilage. To achieve this, the methods usually used are modified atmosphere packaging or the addition of chemical preservatives or often a combination of both these techniques (Al Dagal and Bazaraa, 1999; Mejlholm et al., 2008). In recent years a new approach called biopreservation consisting in preventing the growth of unwanted microorganisms in seafood, by using added microorganisms, generally $L A B$, has been increasingly investigated as an alternative to chemical preservatives. The microbial antagonism of $\mathrm{LAB}$ against undesirable microorganisms has been attributed in many cases to metabolic products such as organic acids or bacteriocin production (Diop et al., 2009; Greer and Dilts 2006; Mataragas et al., 2003; Pridmore et al., 2008; Smith et al., $2005)$ and changes in the physico-chemical environment $\left(\mathrm{pH}, \mathrm{CO}_{2}\right.$ production) or a combination of these factors. Recent works have shown that the inhibition of undesirable bacteria may be correlated to substrate competition (Nilsson et al., 2005). An atypical strain of Lactococcus piscium isolated from fresh salmon steak packed under modified atmosphere (Matamoros et al., 2009a) showed a wide spectrum of activity in a model medium including $B$. thermosphacta. This strain revealed capacities for enhancing the shelf life and sensory quality of naturally contaminated seafood product such as shrimp and salmon without bacteriocin production, but no correlation was found between microbial counts (total viable counts, Enterobacteriacea, LAB) and sensory quality (Matamoros et al., 2009a). Fall et al. (2010a) demonstrated that, this strain could limit the growth of $B$. thermosphacta and thus improve the sensorial quality of cooked shrimp; however, these activities were not linked to any specific metabolism of the strains.

This study was performed to evaluate the spoiling potential of $B$. thermosphacta and the relationship between its growth, metabolite production and sensory degradation observed during storage of tropical cooked peeled shrimp. The metabolism of $L$. piscium and its role as a protective culture were also investigated, as well as the mechanisms involved in its antagonistic effect on $B$. thermosphacta.

\section{Materials and methods}

\subsection{Strains, media and culture conditions}

Isolates came from the Ifremer/Oniris culture collection. L. piscium CNCM I-4031 (formerly L. piscium EU2241) was isolated from fresh salmon steak packed under MA (Matamoros et al., 2009b) and B. thermosphacta CD 340 from brined tropical cooked peeled shrimp packed under MA (Jaffrès et al., 2009). For all the experiments, strains were subcultured twice 
successively for $24 \mathrm{~h}$ at $26^{\circ} \mathrm{C}$ in Elliker broth (Biokar) for L. piscium and $24 \mathrm{~h}$ at $20^{\circ} \mathrm{C}$ in Brain Heart Infusion (Biokar, Diagnostic Beauvais, France) for $B$. thermosphacta.

\subsection{Sterile shrimp preparation}

$31 \mathrm{~kg}$ of frozen tropical peeled and beheaded shrimp (Penaeus vannamei) farmed in Colombia (51/60 size i.e. 51 to 60 shrimps per pound) was obtained from a local production site, Miti industry (Nantes, France). Frozen shrimp were cooked at ONIRIS with industrial equipment by immersion in boiling salted water $(3 \% \mathrm{NaCl} w / \mathrm{v})$ for $2.5 \mathrm{~min}$ after re-ebullition and cooled in melting ice with $1.5 \%$ salt. The shrimp were vacuum packed in plastic bags (1 $\mathrm{kg} / \mathrm{bag}$ ) and stored at $-80^{\circ} \mathrm{C}$ for 9 days. The frozen cooked peeled shrimp were then sterilized by ionisation at $3.76 \pm 0.16 \mathrm{kGy}$ (IONISOS, Pouzauges, France).

\subsection{Challenge tests}

The cells were not washed before inoculation, but serial dilutions in salted peptone water $(0.85 \% \mathrm{NaCl}, 0.1 \%$ peptone) were performed to obtain the appropriate inoculum size. Shrimp were inoculated by spraying $10 \% \mathrm{v} / \mathrm{w}$ ( $5 \%$ of pure culture $+5 \%$ of water or $5 \%$ of protective culture $+5 \%$ of target strain for co-inoculation batch) onto the surface of the shrimp to reach a final level of approximately $7 \log C F U / g$ and $3 \log C F U / g$ for $L$. piscium and $B$. thermosphacta respectively. After inoculation, the samples were tumbled manually to ensure good microbial distribution.

Four batches of shrimp were used with different treatments: 1-sterility control, 2-inoculated with $L$. piscium, 3- inoculated with $B$. thermosphacta, 4- co-inoculated with $B$. thermosphacta and $L$. piscium. After inoculation, the shrimp were packed in $125 \mathrm{~g}$ portions under MA (50\% $\mathrm{N}_{2}-50 \% \mathrm{CO}_{2}$ ) (Multivac T252, Wolfertschwenden, Germany) with a shrimp/gas ratio of approximately $2 / 1$. Samples were stored at $8^{\circ} \mathrm{C}$ for up to 31 days and removed after $1,3,7$, $10,14,17,24$ and 31 days storage for microbial, physico-chemical $(\mathrm{pH}$, acetic and lactic acids, total volatile basic nitrogen (TVBN), trymethylamine oxide (TMA-O), trimethylamine (TMA), sugar, volatile compounds, biogenic amines, free amino-acids) and sensory analysis. All the analyses were performed in triplicate, in three separate punnets.

To investigate whether the antimicrobial activity of L. piscium was caused by its acid production, a new batch of shrimp was inoculated $(5 \% \mathrm{v} / \mathrm{w})$ by $B$. thermosphacta as described previously, portioned in $125 \mathrm{~g}$ packets and stored under the same conditions. After 7 days, all the packets were opened and half of them were sprayed with $5 \%(\mathrm{v} / \mathrm{w})$ water and half with $5 \%(\mathrm{v} / \mathrm{w})$ sodium lactate solution $(44.7 \mathrm{~g} / \mathrm{L})$, in order to reach the maximum concentration of lactic acid naturally produced by $L$. piscium measured in this study. The shrimp were packed again under MA and $B$. thermosphacta was enumerated on days 0,7 , 14 and 24.

\subsection{Microbial analysis}

At each sampling time, the shrimp ( $20 \mathrm{~g})$ were taken aseptically and transferred in stomacher bags containing $80 \mathrm{ml}$ of saline peptone water and then blended with a Stomacher 400 (Seward Medical, London, UK) at normal speed for 2 min at room temperature. L. piscium, either alone or in co-inoculation, was selectively enumerated on spread plates of Elliker agar incubated at $8^{\circ} \mathrm{C}$ for $96 \mathrm{~h}$ under anaerobiosis (Fall et al., 2010b). B. thermosphacta was enumerated $\left(20^{\circ} \mathrm{C}, 48 \mathrm{~h}\right)$ on Streptomycin Sulfate Thallous Acetate Agar with selective supplement (Oxoid, Hampshire, UK). TVC was estimated in the control once a week, by pour plating in Plate Count Agar (Biokar) before incubation at $26^{\circ} \mathrm{C}$ for $48 \mathrm{~h}$. 


\subsection{PCR-TTGE analysis}

The temporal temperature gradient gel electrophoresis (TTGE) technique, a cultureindependent method, was used to track the evolution of bacteria on days 1, 7, 14 and 17. For each batch, $10 \mathrm{ml}$ of each triplicate of the mother solutions from microbial analysis were pooled. Bacterial DNA extraction, PCR amplification of the variable V3 region of 16S rRNA gene with V3P2 and V3P3-GC-Clamp primers and TTGE analysis were performed as described by Jaffrès et al. (2009) in duplicate. 16S rRNA V3 amplicons from a mix of 10 species currently found in shrimp and including $B$. thermosphacta CD340 was used as a marker for bacterial presumptive identification and L. piscium CNCM I-4031 was run alone for control.

\subsection{Sensory evaluation}

Twelve panellists belonging to an internal Ifremer panel with long-term training and experience in seafood evaluation were asked to characterise the influence of each strain on cooked peeled shrimp odours. They had to identify the level of spoilage of the sample by using a four-class scheme (class I: non spoiled, class II: lightly spoiled, class III: moderately spoiled, class IV: strongly spoiled) and then carry out conventional profiling (ISO, 2003) as described by Matamoros et al. (2009a). Odour descriptors were rice/crustacean, butter/caramel, pyrrolidin/sperm, floorcloth, sour/fermented, amine, cheese/foot and cabbage/ $\mathrm{H}_{2} \mathrm{~S}$. The shrimp of each package were distributed in four small plastic drums covered with aluminium foil ( 3 shrimp per drum) and stored at $4^{\circ} \mathrm{C}$ to keep the odour intact. Shrimp were removed from storage at $4^{\circ} \mathrm{C} 15 \mathrm{~min}$ before the test and left at room temperature. The samples were coded and served in random order to the panellists. A quality coefficient (QC) taking into account the level of spoilage with an arbitrary weighting factor attributed to each class was calculated as follows : $Q C=[(1 \times \%$ of answers in class I) $+(2 \times \%$ of answers in class II $)+(3 \times \%$ of answers in class III $)+(4 \times \%$ of answers in class IV)] / 100. QC varied from 1 (nonspoiled product, $100 \%$ of the panellists having judged the product as nonspoiled) to 4 (strongly spoiled product, $100 \%$ of the panellists having scored the product in class IV). The profile data were treated by variance analysis with two factors (product and judge effects). Multivariate data processing in the form of principal component analysis (PCA) was performed on the mean sample sensory scores with Uniwin 6.1 software (Sigma Plus, Paris, France). This PCA was based on the correlation matrix, in order to give the same importance to all the attributes whatever the range of the scale used. On day 31, four panellists, who had been informed of the experiments, ate 3 shrimp inoculated by $L$. piscium and compared them to the control (taste and texture).

\subsection{Biochemical analysis}

Prior to inoculation, shrimp characteristics $(\mathrm{pH}$, salt content, proteins, lipids and water content) were determined as described by Fall et al. (2010b). TMA-O, TMA and TVBN were measured in duplicate in the replicates, using the method described by Conway and Byrne (1933) on a $100 \mathrm{~g}$ portion of shrimp. Lactic and acetic acids were analysed with the enzymatic UV $340 \mathrm{~nm}$ test kit 021 (Biosentec, Toulouse, France), by using an extraction method proposed by Fall et al. (2010b). Sugar content was measured by a modified (water extraction instead of TCA extraction) colorimetric method of Dubois et al. (1956). Biogenic amine and volatile compounds were analysed in triplicate on days 1 and 14 . A fraction of 1.5 $\mathrm{ml}$ of the five-fold dilution used for microbial analyses was kept at $-80^{\circ} \mathrm{C}$ and used for biogenic amine quantification. Putrecine, cadaverine, histamine, tyramine, spermine and spermidine were analysed by high pressure liquid chromatography (HPLC) using a Kromasil reversed phase column C18 $(5 \mu \mathrm{m}, 25 \mathrm{~cm} \times 4.6 \mathrm{~mm})$ fitted with a Brownlee C18 precolumn $(5 \mu \mathrm{m}, 3 \mathrm{~cm} \times 4.6 \mathrm{~mm})$ according to Duflos et al. (1999). Free amino acids content was determined in all batches at day 1 and day 14 by using the amino acid analyser Biochrom 30 
(Biochrom, Cambridge, United Kingdom) at LAREAL Food Research Laboratory, Vannes, France.

Analysis of volatile compounds was performed using a solid phase micro extraction coupled with a gas chromatograph interfaced with a mass spectrometer (SPME/GC-MS). For each batch, a $20 \mathrm{~g}$ portion of shrimp was individually introduced into a stomacher bag and $50 \mathrm{ml}$ of $\mathrm{NaCl}$ saturated water $(300 \mathrm{~g} / \mathrm{l})$ added. Samples were blended with a stomacher Lab-blender 400 Seward (Norfolk, USA) and $25 \mathrm{ml}$ of the resulting aqueous phase was transferred into tubes and centrifuged at $10000 \mathrm{~g}, 10 \mathrm{~min}, 4^{\circ} \mathrm{C}$. Eleven millilitres of the supernatant were transferred to $20 \mathrm{ml}$ vials to which $10 \mu \mathrm{l}$ of 3-methyl-3-buten-1-ol (internal standard) was added. All the vials were sealed and then placed in the sample tray of the Combi Pal AOC5000 auto injector system at $4^{\circ} \mathrm{C}$. The samples were heated to $50^{\circ} \mathrm{C}$ and mixed at $500 \mathrm{rpm}$ for $10 \mathrm{~min}$ to adsorb volatile compounds in the headspace of the vials. SPME fiber, $75 \mu \mathrm{m}$ Carbonex/Polydimethylsiloxane (Supelco, Bellefonte, PA, USA) was inserted into the septum of the vials and exposed for 40 min for volatile sorption. The fibre was then introduced through the injector port of the chromatograph for $10 \mathrm{~s}$ at $250^{\circ} \mathrm{C}$ to desorb volatile compounds. The GC (Shimadzu, Kyoto, Japan) equipped with a SLB-5ms fused silica capillary column ( $60 \mathrm{~m} \times 0.25 \mathrm{~mm} \times 0.25 \mu \mathrm{m}$ film thickness) from Sigma Aldrich (St.Louis, MO, USA) was coupled to a Shimadzu MS detector QP2010 Plus. The injection port was kept at $250^{\circ} \mathrm{C}$ in splitless mode. The flow rate of the carrier gas (helium) was $1.78 \mathrm{ml} / \mathrm{min}$; the temperature of the column was maintained at $35^{\circ} \mathrm{C}, 5 \mathrm{~min}$ and then progressively increased from 35 to $100^{\circ} \mathrm{C}$, first in the flow at $10^{\circ} \mathrm{C} \mathrm{min}{ }^{-1}$, and then from $100^{\circ} \mathrm{C}$ to $280^{\circ} \mathrm{C}$ at $20^{\circ} \mathrm{C} \mathrm{min}{ }^{-1}$ and maintained for $5 \mathrm{~min}$. The MS detector was operated in electron ionisation mode $(70 \mathrm{eV})$ and the ion source temperature was maintained at $200^{\circ} \mathrm{C}$. A continuous scan mode was used with a mass range from 33 to $200 \mathrm{~m} / \mathrm{z}$. Volatile compounds were identified by matching their mass spectra to those contained in the NIST 2008 mass spectral database (developed for Shimadzu by NIST). Analysis of variance (ANOVA) with the LSD multiple range test, was performed with Statgraphics Plus Centurion XV.I software (Sigma Plus) on the means of volatile compounds and free amino acids. The significant level was set at $p<0.05$.

\section{Results}

\subsection{Shrimp characteristics}

The shrimp studied contained $73.0 \pm 0.5 \%$ of water, $22.1 \pm 0.0 \%$ of proteins, $0.52 \pm 0.04 \%$ of carbohydrates, $0.5 \pm 0.0 \%$ of lipid and $1.24 \pm 0.02 \%$ of $\mathrm{NaCl}$.

\subsection{Microbial growth in shrimp}

In the uninoculated batches, no colony was detected by plate count agar (threshold $5 \mathrm{CFU} / \mathrm{g}$ ) throughout the experiment, confirming that the ionisation dose is sufficient to ensure the bacterial stability of the product. Figure 1 shows the growth kinetics of $L$. piscium and $B$. thermosphacta in pure and mixed cultures. The growths of $L$. piscium alone or in presence of $B$. thermosphacta were similar. Within the first 4 days of the challenge test at $8^{\circ} \mathrm{C}, \mathrm{L}$. piscium numbers increased by $2.0 \pm 0.1 \mathrm{log}$ CFU/g cycles to reach a maximum of $9.1 \pm 0.1 \mathrm{log} \mathrm{CFU} / \mathrm{g}$ and remained constant till the end of the experiment. $B$. thermosphacta increased from an initial level of $3.7 \pm 0.8 \log$ CFU/g up to $8.7 \pm 0.1 \mathrm{log}$ CFU/g in 10 days and over. When inoculated with $L$. piscium, B. thermosphacta reached its maximum number of $5.5 \pm 0.2 \mathrm{log}$ $\mathrm{CFU} / \mathrm{g}$ in 7 days. Then the growth was stopped and the count remained constant until 31 days storage, corresponding to a $3.2 \pm 0.1 \log \mathrm{CFU} / \mathrm{g}$ reduction when compared to $B$. thermosphacta alone. 


\subsection{TTGE analysis}

TTGE fingerprints of the V3 region of 16S rRNA gene analysis were assessed in the bacterial ecosystem monitored in order to compare the results from this technique to those from microbial counts. According to unpublished results obtained in our laboratory, the detection limit of the TTGE technique for a pure culture of bacteria is $4 \log \mathrm{CFU} / \mathrm{mL}$. The results obtained on days 1,7 and 14 are presented in Figure 2 (results at day 17 are similar to day 14). In the control no band was recorded at any analysis point, confirming the sterility of the matrix, whereas a highly intense band fitting to the migration position of $L$. piscium was observed on days 0,7 and 14 in the batch inoculated with the protective culture alone, corresponding to L. piscium counts of appro. 7, 9 and 9 log CFU/g respectively. For $B$. thermosphacta alone on day 1 (3.7 log CFU/g), no band was detected whereas on days 7 and 14, when counts reached approximately7 and $9 \log$ CFU/g respectively, a migration band assigned to $B$. thermosphacta was detected. In coculture, the band corresponding to $L$. piscium was always present, whereas no band was detected for $B$. thermosphacta, whose number ranged between 3 and 5 log CFU/g throughout storage.

\subsection{Sensory evaluation}

In plane 1-2 of the PCA performed with the sensory characteristics of the samples (Figure 3), the first axis (75\% inertia) discriminated fresh samples with rice and crustacean odours (left part of PCA) from spoiled samples with amine, cheese/foot, sour/fermented, pyrrolidin and butter/caramel odours (right part). The second axis (11\% inertia) opposed samples with milky notes (upper part) with $\mathrm{H}_{2} \mathrm{~S} / \mathrm{cabbage}$ and floorcloth off-odours (lower part). The evolution of $\mathrm{QC}$ is shown in Figure 4. During the first 4 days of the experiment, the QC of all batches was below 2, as with the control, and no off-odour was detected (samples in the left part of the PCA). On day 7 the batch inoculated with $B$. thermosphacta was characterised by a slightly cheese/foot and pyrrolidin/sperm odour with a quality index of $2.6 \pm 0.7$. After 10 days, most of the panellists judged the sample as spoiled or strongly spoiled and QC varied from $2.9 \pm$ 0.8 to $3.4 \pm 0.4$ throughout storage. Sensory rejection (day 10 ) occurred when the cell number of $B$. thermosphacta reached 8-9 log CFU/g. The samples were clustered in the right part of PCA and mainly characterised by butter/caramel and sour/fermented off-odours. On the contrary, when B. thermosphacta was co-inoculated with L. piscium, the QC of the product was below 2 for 38 days and the samples were clearly clustered in the left part of the PCA, with rice/crustacean odour typical of fresh shrimp. L. piscium alone did not spoil the product, except on day 38 when very slight floorcloth odours were detected. The samples were in the same cluster as L. piscium with B. thermosphacta (Figure 3 ) and the QC was always lower than 2. At the end of the experiments, four judges ate the products inoculated by $L$. piscium and did not perceive any off-flavour or acid notes.

\subsection{Volatile compounds analysis}

The initial TVBN concentration in the control was $10.8 \pm 0.2 \mathrm{mg}-\mathrm{N} / 100 \mathrm{~g}$. A slight increase up to $13.7 \pm 0.7 \mathrm{mg}-\mathrm{N} / 100 \mathrm{~g}$ was observed after 14 days but TVBN concentration decreased on day $24(1.9 \pm 0.1 \mathrm{mg}-\mathrm{N} / 100 \mathrm{~g})$. The same concentration patterns were observed for samples inoculated with $L$. piscium and $B$. thermosphacta alone or in mixed culture. The initial TMAO concentration in shrimp was $2.5 \pm 0.1 \mathrm{mg}-\mathrm{N} / 100 \mathrm{~g}$. In the control no TMA was measured throughout the experiment. $B$. thermosphacta produced a slight amount of TMA $(4.2 \pm 0.1$ $\mathrm{mg}-\mathrm{N} / 100 \mathrm{~g}$ ) over 14 days. L. piscium alone did not produce TMA alone or in co-culture with B. thermosphacta (Table 1).

About 72 volatile compounds were detected by SPME/GC-MS and identified in all batches. The compounds present in the air and saline diluent and those that were not present in triplicate in studied batches were eliminated and finally, 23 molecules of interest including ketones, alcohols, aldehydes and hydrocarbons were taken into consideration to compare 
the batches (Table 2). In the control, the concentration of certain compounds increased or decreased from day 1 to 14 and new molecules of autolytic origin were also detected. On day 14, B. thermosphacta produced 6 new compounds: 2,3 butanedione, 2-pentanone, 3hydroxy-2-butanone, 2-pentanol, 3-methyl-1-butanol and 4-methyl-3-chloro-2-pentanol. A significant increase of ethanol, 3-methyl-1-butanal, 2-methyl-1-butanal and hydrocarbon benzene as well as the total disappearance of 3-methyl-2-pentanone and 1-butanol were also noticed. L. piscium produced the same molecule, except 4-methyl-3-chloro-2-pentanol, and did not consume 1-butanol. The batch with mixed culture was mainly characterised by a production of heptanal and the absence of 2-pentanol, cyclopentanol, 3-methyl-1-pentanol and 2-methyl-1 butanal. Statistical tests showed that 2,3 butanedione, 3-methyl-1-butanol, 4methyl-3-chloro-2-pentanol, 3-methyl-1-butanal, 2-methyl-1-butanal and hydrocarbons benzene were significantly $(P \leq 0.05)$ more concentrated in the batch with $B$. thermosphacta, characterised by strong off-odours, than in unspoiled batches with $L$. piscium alone or mixed with $B$. thermosphacta.

\subsection{Biogenic amines}

In the control after 14 days storage, neither histamine nor spermine were detected while tyramine, putrescine, cadaverine and spermidine were at very low levels $(1.8 \pm 0.1 \mathrm{mg} / \mathrm{kg}$, $1.8 \pm 0.2 \mathrm{mg} / \mathrm{kg}, 4.2 \pm 0.3 \mathrm{mg} / \mathrm{kg}$ and $2.8 \pm 0.2 \mathrm{mg} / \mathrm{kg}$ respectively). No biogenic amine production was observed in the batches inoculated by $L$. piscium and $B$. thermosphacta alone and in combination (data not shown).

\subsection{Glucose, lactic acid and free amino acid determination}

The analysis of substrates or metabolites such as free amino acids, glucose and lactic acid was performed in order to determine their possible involvement in the antagonistic mechanism of the protective L. piscium strain.

Free amino acids profile of tropical cooked peeled shrimp on day 1 ( Table 3 ) showed a high level content of proline (3178 $\pm 252 \mathrm{mg} / \mathrm{kg})$, arginine $(3149 \pm 132 \mathrm{mg} / \mathrm{kg})$ and glycine $(2575 \pm$ $64 \mathrm{mg} / \mathrm{kg}$ ) respectively. On the other hand, aspartic acid, ornithine, threonine, isoleucine and phenylalanine were found in weak concentration (lower than $90 \mathrm{mg} / \mathrm{kg}$ ). Cysteine, methionine and tryptophan were not detected. After 14 days of storage, a statistically significant difference in isoleucine concentration, in term of consumption, was established between batch inoculated with $B$. thermosphacta and non-inoculated batch (Table 3).

Mean carbohydrate concentration in Penaeus vannamei shrimp, probably corresponding to glucose, as demonstrated by Fall et al. (2010a), was $0.52 \pm 0.04 \%$. L. piscium consumed sugar very quickly, with concentration dropping to $0.36 \pm 0.00$ and $0.16 \pm 0.03 \%$ in 1 and 3 days respectively and then remaining at this level until 31 days. The same values (no significant difference) were observed in co-culture. B. thermosphacta alone also consumed glucose, total consumption being observed on day $7(0.13 \pm 0.02 \%)$. pH and L-lactate production are shown in Figure 5. No acetic acid was detected in the samples. Shrimp is naturally rich in lactate $(1680 \pm 60 \mathrm{mg} / \mathrm{kg})$. Both $L$. piscium and $B$. thermosphacta produced L-lactate. The maximum concentration observed was $3530 \pm 130 \mathrm{mg} / \mathrm{kg}$, corresponding to an increase of $1850 \mathrm{mg} / \mathrm{kg}$, after 3 and 10 days respectively for $L$. piscium and $B$. thermosphacta, although a fall on day 7 for $B$. thermosphacta was observed. In co-inoculated batches, lactate concentration reached $5510 \pm 180 \mathrm{mg} / \mathrm{kg}$ on day 7 , representing a production of $3830 \pm 225 \mathrm{mg} / \mathrm{kg}$, which is far higher than the addition of $L$. piscium and $B$. thermosphacta production. Thereafter the concentration in the co-inoculation batch was the same as with $L$. piscium alone. The mean $\mathrm{pH}$ value of the sterile shrimp was constant $(6.56 \pm$ 0.02 ) throughout the experiment. A rapid drop in $\mathrm{pH}$ to $6.05 \pm 0.11$ in 3 days was observed in 
batches inoculated with $L$. piscium alone or in co-culture. A similar variation was also noticed after day 10 with $B$. thermosphacta (Figure 5).

In order to assess the effect of lactate produced by $L$. piscium on the inhibition of $B$. thermosphacta, the growth of the latter was monitored in the presence of the maximum lactate concentration produced by the protective strain $(1850 \mathrm{mg} / \mathrm{kg})$ and compared to growth without the addition of lactate. No significant difference was observed for the growth of $B$. thermosphacta under these two conditions (data not shown).

\section{Discussion}

In this study, the growth of $L$. piscium CNCM I-4031 and the spoilage microorganism $B$. thermosphacta in cooked peeled shrimp at $8^{\circ} \mathrm{C}$ as well as the effect of their metabolites on sensory quality was evaluated. This temperature was chosen because it feigns the temperature usually observed in consumer's fridge. Moreover, the protocol of shelf-life validation for cooked/peeled shrimp stored under MAP, in the French good manufacturing and hygienic practise guide, always includes a period at $8^{\circ} \mathrm{C}$. The rapid growth of $L$. piscium and $B$. thermosphacta corroborates the fact that these two bacteria are psychrotrophic and can catabolise shrimp meat substrates for their growth.

Adaptation of $B$. thermosphacta in such matrixes has been already demonstrated by Laursen et al. (2006), as an increase from less than $1 \mathrm{log}$ CFU/g to $4.5 \mathrm{log}$ CFU/g after ten days at $5^{\circ} \mathrm{C}$ was observed in Nordic cooked shrimp. Mejlholm et al. (2005) also proved that $B$. thermosphacta can reach 8 log CFU/g in cooked peeled Nordic shrimp stored at 2, 5 and $8^{\circ} \mathrm{C}$. As shown previously by Fall et al. (2010b), L. piscium confirmed its adaptation on shrimp and its colonisation during the storage was also demonstrated using the TTGE technique. TTGE or DDGE was useful for monitoring protective flora, as shown by Vasilopoulos et al. (2010) in cooked ham stored under MAP. TTGE also permitted the detection of $B$. thermosphacta on day 7 before rejection of the samples by the sensory panel, and thus could be used as an alternative detection method for spoiling microbial indicators. In co-culture, species representing less than $1 \%$ of the total community are not visible in TTGE profiles (Muyzer et al., 1993; Ogier et al., 2002). Although not quantitative, the results obtained in co-culture (absence of $B$. thermosphacta and presence of $L$. piscium fingerprints) demonstrated the efficiency of this technique by revealing the inhibition of one bacterial population by another.

When growing, the metabolic activity of $B$. thermosphacta spoiled the product with the emission of off-odours. TMA resulting from the bacterial reduction of TMAO under anaerobic condition and TVBN are often used as spoilage indicators for fish and seafood products. The production of these compounds by $B$. thermosphacta was not significant in shrimp, as it has already been shown in cold-smoked salmon by Stohr et al. (2001). These compounds were found to be poor quality indices for naturally contaminated cooked shrimp (Dalgaard and Jorgensen, 2000; Mejlholm et al., 2005) and for raw peeled royal shrimp Penaeus kerathurus (Sadok et al., 2004). The low initial level of TMAO in topical shrimp may explain the weak production of TMA observed in this study, both by the Conway and SPME-GC-MS. Contrary to what has been determined for other seafood products (Jorgensen et al., 2000; VecianaNogues et al., 1997), biogenic amines could not be retained as spoilage indicators since they were not produced by $B$. thermosphacta at the time of rejection. The same observations were made by Mejlholm et al. (2005).

The strong butter/caramel off-odour detected in our study has also been attributed to $B$. thermosphacta by Laursen et al. (2006) and Mejlholm et al. (2005) after ten days storage at $5^{\circ} \mathrm{C}$ in cooked, peeled Nordic shrimp. This off-odour is usually correlated to diacetyl 
production (2,3-butanedione) whose production was significantly higher in the batch inoculated with $B$. thermosphacta than in the batches in which $L$. piscium was present and which were not rejected by the panel. For Laursen et al. (2006), in addition to diacetyl, other volatile compounds like 3-methyl-1-butanal and 3-methyl-1-butanol may explain the formation of off-odours by $B$. thermosphacta. In our study, these two compounds were also over-produced in batches inoculated by $B$. thermosphacta. 2,3-butanedione and 3-methyl-1butanol stem from the pyruvate metabolism, whereas for Carnobacterium spp. and E. coli (Connor et al., 2010; Larrouture-Thiveyrat and Montel, 2003) 3-methyl-1 butanal is known to stem from leucine metabolism, one of the main amino acids measured in shrimp (Fall et al., 2010a). It is however notable to observe that these 3 volatile compounds, although in lesser quantity, were also produced in the batches inoculated by L. piscium without the detection of any off-odours. Concentration of these molecules was not measured and the relation with the sensory perception remains unknown. These metabolites were probably under the olfactory threshold in the case of $L$. piscium and thus not detected by the sensory panel. It is likely that 4-methyl-3-chloro-2-pentanol, which is only produced by $B$. thermosphacta, and the production of ethanol, 1-penten-3-ol, cyclopentanol, 2-methyl-1-butanal and hydrocarbons benzene that are significantly greater in $B$. thermosphacta compared to other batches on day 14, could participate in the off-odours of the products. All these compounds, except for cyclopentanol and 4-methyl-3-chloro-2-pentanol, were identified previously by Laursen et al. (2006) and Vasilopoulos et al. (2010) in cooked peeled MAP shrimp and cooked ham inoculated with $B$. thermosphacta. The production of 2-heptanone and 2-hexanone by $B$. thermosphacta in cold-smoked salmon, leading to blue cheese off-odour (Joffraud et al., 2001) has not been shown in shrimp.

The production of diacetyl has been associated with the aerobic metabolism of $B$. thermosphacta (Dainty et al., 1979; Laursen et al., 2006; Leroy et al., 2009; Pin et al., 2002). In our study after the first day of incubation at $8^{\circ} \mathrm{C}$, the concentration of $\mathrm{CO}_{2}$ decreased to 25 $\%$ due to absorption in the shrimp flesh (the relation between $\mathrm{CO}_{2}$ in the packaging gas and in the headspace at equilibrium at $8^{\circ} \mathrm{C}$ predicts $35 \%$ with a $2 / 1$ gas/fish ratio and $25 \%$ with $1 / 1)$. This phenomenon was followed by an alternate increase and decrease that has already been observed by Mejlholm et al. (2005) and could be linked to the fermentative metabolism of the strains and permeability of the packaging film. Some authors suggested that higher $\mathrm{CO}_{2}$ concentration in MAP could reduce the spoilage potential of $B$. thermosphacta in cooked peeled shrimp (Laursen et al., 2006), however, higher concentrations lead to acidic taste. Our study showed that at $8^{\circ} \mathrm{C}$ an atmosphere of $50 \% \mathrm{CO}_{2}-50 \% \quad \mathrm{~N}_{2}$ without $\mathrm{O}_{2}$ was not efficient enough to limit the production of butter-like off-odours. However it has been shown for other bacteria such as Listeria monocytogenes that at lower temperature $\left(2^{\circ} \mathrm{C}\right)$, the solubility of $\mathrm{CO}_{2}$ combined to the effect of the temperature was more efficient to reduce its growth in cooked MAP shrimp (Meijholm et al., 2005). Additional hurdles such as the protective bacteria $L$. piscium $\mathrm{CNCM}$ I-4031 delayed the undesirable sensory changes caused by $B$. thermosphacta and led to extending the shelf-life of cooked peeled shrimp. The effectiveness of $L$. piscium as a protective culture was demonstrated in a previous study for 21 days storage (Fall et al., 2010a) and is confirmed here for 31 days storage with no adverse effects on sensory quality of the biopreserved product. In the samples inoculated with $L$. piscium, the volatile compounds detected were similar to those inoculated with $B$. thermosphacta, but with a significantly lower amount for most of them. Diacetyl is an end product of the citric acid metabolism of $L A B$, including species belonging to the genus Lactococcus (Bartowsky, 2009; Jay, 1982) and this property is often used in the food industry for generating buttermilk flavour. In shrimp however, the production of diacetyl by L. piscium was not detected by smell or taste. The drop in $\mathrm{pH}$ and in lactic acid production by the lactic protective strain was not considered negative by the panel and the absence of TVBN, TMA and biogenic amine production confirmed the neutrality of the protective strain on this product. The absence of histamine and tyramine is also an important positive point for food applications. 
B. thermosphacta was inhibited by L. piscium by more than $3 \log$ CFU/g. Laursen et al. (2006) failed to demonstrate the efficacy of Carnobacterium. maltaromaticum cluster $L$ as a protective culture on the sensory quality of cooked peeled MAP shrimp inoculated with $B$. thermosphacta, although positive results had been obtained in a Petri dish. To our knowledge, no extension of shelf-life has been obtained in shrimp by using biopreservation technology. Al Dagal and Bazaraa (1999) had little success with Bifidobacterium breve on either whole or peeled Penaeus sp. at $0^{\circ} \mathrm{C}$. Einarsson and Lauzon (1995) extended the shelflife of brine $P$. borealis with crude extract of bacteriocins (bavaricin A and nisin Z), but did not test for live bacteria. Most of the promising studies concerning the specific inhibition of $B$. thermopshacta by LAB have been performed on meat products. Castellano et al. (2010), Vasilopoulos et al. (2010) and Vermeiren et al. (2006a, b) have successfully improved the shelf-life of different meat products with selected Leuconostoc carnosum and Lactobacillus sakei strains that inhibited $B$. thermosphacta but the application was limited due to acidic flavours in the inoculated products. Despite a glucose concentration close to those of certain cooked meat products, the final $\mathrm{pH}$ in shrimp inoculated by the protective $L$. piscium strain remains higher than in meat (5.9 versus 5.2 to 5.8), probably due to the higher initial $\mathrm{pH}$ and higher buffering capacity of shrimp meat. The antimicrobial activity mechanism of $L$. piscium against $B$. thermosphacta has not yet been elucidated. Previous works rejected the hypothesis of bacteriocin production (Matamoros et al., 2009a) and pH diminution (Fall et al., 2010a). The current study shows that each strain produces equivalent amounts of lactic acid when their bacterial population is maximal. The same results were observed by Vermeiren et al. (2006a) and Vasilopoulos et al. (2010) when comparing the lactic acid production of protective $L A B$ and $B$. thermosphacta in cooked ham and meat model media. The results of $B$. thermosphacta growth in the presence of lactic acid confirmed that the antagonism of $L$. piscium is not only due to lactic acid production and that nutrient competition may be involved. Indeed, the rapid use of glucose by the $L$. piscium strain in shrimp coincided with the termination of $B$. thermosphacta development. Glucose competition has already been demonstrated in the inhibition of $L$. monocytogenes by a strain of $C$. maltaromaticum (Nilsson et al., 2005). On the other hand, Vermeiren et al. (2006a) claimed that the inhibition between $B$. thermosphacta and $L$. sakei could not be due to glucose consumption since the antagonistic effect was equivalent in model media with both high and low glucose content. Concerning amino acid consumption that was assessed at day 14 when the population level of the two bacteria was stable and the maximal inhibition obtained, the current study shows that, except for isoleucine that is consumed by $B$. thermosphacta, none of the 19 compounds analysed was used by any of the two strains. For $B$. thermosphacta these results are in agreement with those of Laursen et al. (2006) for arginine, ornithine and tyrosine but the consumption of leucine observed in Nordic shrimp stored at $5^{\circ} \mathrm{C}$ was not recorded here. However, it is clear that the antagonistic mechanism of $L$. pisicum is not linked to a competition for free amino acids. Further studies on nutrient competition for other nutrients such as nucleotides or vitamins are currently in progress in our laboratory, using chemically defined model media. It is not excluded that the quorum sensing phenomenon may also be involved. The inhibition of $B$. thermosphacta may explain the extension of sensory shelf-life of naturally contaminated shrimp observed by Matamoros et al. (2009a). The study of the effect of environmental parameters (MAP, temperature, etc.) influencing the protective effect of $L$. piscium will be also required in order to improve the use of protective cultures in shrimp and other seafood products, in combination with product formulations and processes.

\section{Acknowledgements}

The authors are grateful to Frédérique Chevalier for her assistance in experiment preparation. 


\section{References}

Al Dagal, M.M., Bazaraa, W.A., 1999. Extension of shelf life of whole and peeled shrimp with organic acid salts and Bifidobacteria. Journal of Food Protection 62, 51-56.

Bartowsky, E.J., 2009. Bacterial spoilage of wine and approaches to minimize it. Letters in Applied Microbiology 48, 149-156.

Castellano, P., González, C., Carduza, F., Vignolo, G., 2010. Protective action of Lactobacillus curvatus CRL705 on vacuum-packaged raw beef. Effect on sensory and structural characteristics. Meat Science 85, 394-401.

Connor, M.R., Cann, A.F., Liao, J.C., 2010. 3-Methyl-1-butanol production in Escherichia coli: random mutagenesis and two-phase fermentation. Applied Microbiology and Biotechnology 86, 1155-1164.

Conway, E.J., Byrne, A., 1933. An absorption apparatus for the micro-determination of certain volatile substances. I. The micro-determination of ammonia. Biochemical Journal 27, 419-429.

Dainty, R.H., Shaw, B.G., Charmaigne, D., Harding, C., Michanie, S., 1979. The spoilage of vacuum-packed beef by cold tolerant bacteria. In: A.D. Russell, R. Fuller (Eds.), Cold Tolerant Microbes in Spoilage and the Environment, Academic Press, London, pp. 83-100.

Dalgaard, P., Jorgensen, L.V., 2000. Cooked and brined shrimps packed in a modified atmosphere have a shelf-life of $>7$ months at $0^{\circ} \mathrm{C}$, but spoil in $4-6$ days at $25^{\circ} \mathrm{C}$. International Journal of Food Science and Technology 35, 431-442.

Dalgaard, P., Vancanneyt, M., Euras Vilalta, N., Swings, J., Fruekilde, P., Leisner, J.J., 2003. Identification of lactic acid bacteria from spoilage associations of cooked and brined shrimps stored under modified atmosphere between $0^{\circ} \mathrm{C}$ and $25^{\circ} \mathrm{C}$. Journal of Applied Microbiology 94, 80-89.

Diop, M.B., Dubois-Dauphin, R., Destain, J., Tine, E., Thonart, P., 2009. Use of a nisinproducing starter culture of Lactococcus lactis subsp. lactis to Improve traditional fish fermentation in Senegal. Journal of Food Protection 72, 1930-1934.

Dubois, M., Gilles, K.A., Hamilton, J.K., Rebers, P.A., and Smith, F., 1956. Method for determination of sugars and related substances. Analyse Chemistry, 28 350-356.

Duflos, G., Dervin, C., Malle, P., Bouquelet, S., 1999. Relevance of matrix effect in determination of biogenic amines in plaice (Pleuronectes platessa) and whiting (Merlangus merlangus). Journal of AOAC International 82, 1097-1101.

Einarsson, H., Lauzon, L., 1995. Biopreservation of brined shrimp (Pandalus borealis) by bacteriocins from Lactic Acid Bacteria. Applied and Environmental Microbiology 61, 669-676.

Fall, P.A., Leroi, F., Cardinal, M., Chevalier, F., Pilet, M.F., 2010a. Inhibition of Brochothrix thermosphacta and sensory improvement of tropical peeled cooked shrimp by Lactococcus piscium CNCM I-4031. Letters in Applied Microbiology 50, 357-361.

Fall, P.A., Leroi, F., Chevalier, F., Guérin, C., Pilet, M.F., 2010b. Protective effect of a nonbacteriocinogenic Lactococcus piscium CNCM I-4031 strain against Listeria monocytogenes in sterilized tropical cooked peeled shrimp. Journal of Aquatic Food Product Technology 19, $84-92$. 
Greer, G.G., Dilts, B.D., 2006. Control of meatborne Listeria monocytogenes and Brochothrix thermosphacta by a bacteriocinogenic Brochothrix campestris ATCC 43754. Food Microbiology 23, 785-790.

Huis in't Veld, J.H.J., 1996. Microbial and biochemical spoilage of foods: an overview. International Journal of Food Microbiology 33, 1-18.

ISO, International Organization for Standardization 2003. Sensory analysis-methodologyGeneral guidance for establishing a sensory profile, ISO 13299, Geneva, Switzerland

Jaffrès, E., Sohier, D., Leroi, F., Pilet, M.F., Prévost, H., Joffraud, J.J., Dousset, X., 2009. Study of the bacterial ecosystem in tropical cooked and peeled shrimps using a polyphasic approach. International Journal of Food Microbiology 131, 20-29.

Jay, J.M., 1982. Antimicrobial properties of diacetyl. Applied and Environmental Microbiology $44,525-532$

Joffraud, J.J., Leroi, F., Roy, C., Berdagué, J.L., 2001. Characterisation of volatile compounds produced by bacteria isolated from the spoilage flora of cold-smoked salmon. International Journal of Food Microbiology 66, 175-184.

Jorgensen, L.V., Dalgaard, P., Huss, H.H., 2000. Multiple compound quality index for coldsmoked salmon (Salmo salar) developed by multivariate regression of biogenic amines and $\mathrm{pH}$. Journal of Agricultural and Food Chemistry 48, 2448-2453.

Larrouture-Thiveyrat, C., Montel, M.C., 2003. Effects of environmental factors on leucine catabolism by Carnobacterium piscicola. International Journal of Food Microbiology 81, 177184.

Laursen, B.G., Leisner, J.J., Dalgaard, P., 2006. Carnobacterium species: Effect of metabolic activity and interaction with Brochothrix thermosphacta on sensory characteristics of modified atmosphere packed shrimp. Journal of Agricultural and Food Chemistry 54, 3604-3611.

Leroy, F., Vasilopoulos, C., Van Hemelryck, S., Falony, G., De Vuyst, L., 2009. Volatile analysis of spoiled, artisan-type, modified-atmosphere-packaged cooked ham stored under different temperatures. Food Microbiology 26, 94-102.

Matamoros, S., Leroi, F., Cardinal, M., Gigout, F., Chadli, F.K., Cornet, J., Prevost, H., Pilet, M.F., 2009a. Psychrotrophic lactic acid bacteria used to improve the safety and quality of vacuum-packaged cooked and peeled tropical shrimp and cold-smoked salmon. Journal of Food Protection 72, 365-374.

Matamoros, S., Pilet, M.F., Gigout, F., Prevost, H., Leroi, F., 2009b. Selection and evaluation of seafood-borne psychrotrophic lactic acid bacteria as inhibitors of pathogenic and spoilage bacteria. Food Microbiology 26, 638-44.

Mataragas, M., Drosinos, E.H., Metaxopoulos, J., 2003. Antagonistic activity of lactic acid bacteria against Listeria monocytogenes in sliced cooked cured pork shoulder stored under vacuum or modified atmosphere at $4 \pm 2^{\circ} \mathrm{C}$. Food Microbiology 20, 259-265.

Mejlholm, O., Boknaes, N., Dalgaard, P., 2005. Shelf life and safety aspects of chilled cooked and peeled shrimps (Pandalus borealis) in modified atmosphere packaging. Journal of Applied Microbiology 99, 66-76. 
Mejlholm, O., Kjeldgaard, J., Modberg, A., Vest, M.B., Bøknæs, N., Koort, J., Björkroth, J., Dalgaard, P., 2008. Microbial changes and growth of Listeria monocytogenes during chilled storage of brined shrimp (Pandalus borealis). International Journal of Food Microbiology 124, 250-259.

Muyzer, G., Dewaal, E.C., Uitterlinden, A.G., 1993. Profiling of complex microbial population by denaturing gradient gel - electrophoresis analysis of polymerase chain reaction -amplified genes -coding for $16 \mathrm{~S}$ ribosomal RNA. Applied and Environmental Microbiology 59, 695-700.

Nilsson, L., Hansen, T.B., Garrido, P., Buchrieser, C., Glaser, P., Knochel, S., Gram, L., Gravesen, A., 2005. Growth inhibition of Listeria monocytogenes by a nonbacteriocinogenic Carnobacterium piscicola. Journal of Applied Microbiology 98, 172-183.

Ogier, J.C., Son, O., Gruss, A., Tailliez, P., Delacroix-Buchet, A., 2002. Identification of the bacterial microflora in dairy products by temporal temperature gradient gel electrophoresis. Applied and Environmental Microbiology 68, 3691-3701.

Pin, C., Garcia de Fernando, G.D., Ordonez, J.A., 2002. Effect of modified atmosphere composition on the metabolism of glucose by Brochothrix thermosphacta. Applied and Environmental Microbiology 68, 4441-4447.

Pridmore, R.D., Pittet, A.C., Praplan, F., Cavadini, C., 2008. Hydrogen peroxide production by Lactobacillus johnsonii NCC 533 and its role in anti-Salmonella activity. FEMS Microbiology Letters 283, 210-215.

Sadok, S., Abdelmoulah, A., El Abed, A., 2004. Combinated effect of sepia soaking and temperature on the shelf life of peeled shrimp Penaeus kerathurus. Food Chemistry 88, 115122.

Smith, L., Mann, J.E., Harris, K., Miller, M.F., Brashears, M.M., 2005. Reduction of Escherichia coli $\mathrm{O} 157$ : $\mathrm{H} 7$ and Salmonella in ground beef using lactic acid bacteria and the impact on sensory properties. Journal of Food Protection 68, 1587-1592.

Stohr, V., Joffraud, J.J., Cardinal, M., Leroi, F., 2001. Spoilage potential and sensory profile associated with bacteria isolated from cold-smoked salmon. Food Research International 34, 797-806.

Vasilopoulos, C., De Mey, E., Dewulf, L., Paelinck, H., De Smedt, A., Vandendriessche, F., De Vuyst, L., Leroy, F., 2010. Interactions between bacterial isolates from modifiedatmosphere-packaged artisan-type cooked ham in view of the development of a bioprotective culture. Food Microbiology 27, 1086-1094.

Veciana-Nogues, M.T., Marine.Font, A., Vidal-Carou, M.C., 1997. Biogenic Amines as hygienic quality indicators of tuna. Relationships with Microbial Counts, ATP-Related Compounds, Volatile Amines, and Organoleptic Changes. Journal of Agricultural and Food Chemistry 45, 2036-2041.

Vermeiren, L., Devlieghere, F., Debevere, J., 2006a. Co-culture experiments demonstrate the usefulness of Lactobacillus sakei $10 \mathrm{~A}$ to prolong the shelf-life of a model cooked ham. International Journal of Food Microbiology 108, 68-77.

Vermeiren, L., Devlieghere, F., Vandekinderen, I., Rajtak, U., Debevere, J., 2006b. The sensory acceptability of cooked meat products treated with a protective culture depends on glucose content and buffering capacity: A case study with Lactobacillus sakei 10A. Meat Science $74,532-545$. 
Table 1: Concentration of total volatile basic nitrogen (TBVN) and trimethylamine (TMA) (mg$\mathrm{N} / 100 \mathrm{~g}$ ) in cooked peeled shrimp stored at $8^{\circ} \mathrm{C}$. Values are averages of three analyses \pm standard deviation

\begin{tabular}{|c|c|c|c|c|c|c|c|c|c|c|}
\hline & & & TVBN & & & & & TMA & & \\
\hline days & 1 & 7 & 14 & 24 & 31 & 1 & 7 & 14 & 24 & 31 \\
\hline Control & $10.8 \pm 0.2$ & $10.5 \pm 1.3$ & $13.7 \pm 0.7$ & $1.9 \pm 0.1$ & nd & nd & $0 \pm 0.0$ & $0 \pm 0.0$ & $0 \pm 0.0$ & nd \\
\hline L.piscium & $9.1 \pm 0.7$ & $9.8 \pm 1.5$ & $9.5 \pm 0.2$ & $3 \pm 0.0$ & $1.8 \pm 0.1$ & nd & $0.98 \pm 0.8$ & $1.8 \pm 0.5$ & $0 \pm 0.0$ & $0.6 \pm 0.0$ \\
\hline$B t$ & $6.6 \pm 0.5$ & $9.7 \pm 0.5$ & $14.1 \pm 1.3$ & $2.7 \pm 0.4$ & $1.4 \pm 0.5$ & nd & $1.7 \pm 0.4$ & $4.2 \pm 0.1$ & $0.2 \pm 0.0$ & $1.2 \pm 0.1$ \\
\hline $\begin{array}{l}\text { L.piscium } \\
+B t\end{array}$ & $10.5 \pm 0.4$ & $8.7 \pm 0.1$ & $11.9 \pm 2.7$ & $1.6 \pm 0.3$ & $3.9 \pm 0.3$ & nd & $0 \pm 0.0$ & $1.8 \pm 0.5$ & $0.2 \pm 0.0$ & $0.6 \pm 0.0$ \\
\hline
\end{tabular}

nd not determined 
Table 2: Volatile compounds identified in tropical cooked peeled shrimp inoculated with L. piscium CNCM I-4031 and B. thermosphacta CD340 in pure and mixed culture and stored under modified atmosphere at $8^{\circ} \mathrm{C}$ after 1 day and 14 day.

Values are averages \pm standard deviation of $\log ($ peak area/g). $n=3$.

\begin{tabular}{|c|c|c|c|c|c|c|}
\hline \multirow{2}{*}{$\begin{array}{l}\text { Volatile } \\
\text { compound }\end{array}$} & \multirow{2}{*}{$\begin{array}{l}\text { Retention } \\
\text { Time }\end{array}$} & Day 1 & \multicolumn{4}{|l|}{ Day 14} \\
\hline & & control & control & L. piscium & B.t & L. piscium $+B t$ \\
\hline ketones & & & & & & \\
\hline 2,3-butanedione & 5.07 & nd & $n d^{b, c, d}$ & $6.2 \pm 0.0^{a, c, d}$ & $6.7 \pm 0.0^{\mathrm{a}, \mathrm{b}, \mathrm{d}}$ & $6.4 \pm 0.0^{\mathrm{a}, \mathrm{b}, \mathrm{c}}$ \\
\hline 2-pentanone & 5.15 & nd & $\mathrm{nd}^{\mathrm{b}, \mathrm{c}, \mathrm{d}}$ & $6.4 \pm 0.2$ & $6.5 \pm 0.3$ & $6.1 \pm 0.2$ \\
\hline $\begin{array}{l}\text { 3-hydroxy-2- } \\
\text { butanone }\end{array}$ & 7.75 & nd & $\mathrm{nd}^{\mathrm{b}, \mathrm{c}, \mathrm{d}}$ & $6.6 \pm 0.6$ & $6.8 \pm 0.7$ & $6.2 \pm 0.2$ \\
\hline $\begin{array}{l}\text { 3-methyl-2- } \\
\text { pentanone }\end{array}$ & 5.21 & $6 \pm 0.0$ & $\begin{array}{l}5.7 \pm \\
0.0^{b, c, d}\end{array}$ & $\mathrm{nd}^{\mathrm{a}}$ & $\mathrm{nd}^{\mathrm{a}}$ & $\mathrm{nd}^{\mathrm{a}}$ \\
\hline ethanol & 3.84 & $6.8 \pm 0.1$ & $6.8 \pm 0.1^{c, d}$ & $6.8 \pm 0.1$ & $7.2 \pm 0.1^{\mathrm{a}, \mathrm{b}}$ & $7.3 \pm 0.1^{a, b}$ \\
\hline 2-pentanol & 4.13 & $5.7 \pm 0.0$ & $n d^{\mathrm{b}, \mathrm{c}, \mathrm{d}}$ & $5.5 \pm 0.0^{\mathrm{a}, \mathrm{d}}$ & $5.5 \pm 0.00^{a, d}$ & $\mathrm{nd}^{\mathrm{b}, \mathrm{c}}$ \\
\hline 1-butanol & 6.72 & $5.6 \pm 0.2$ & $5.1 \pm 0.9^{c, d}$ & $5.4 \pm 0.1^{\mathrm{c}, \mathrm{d}}$ & nd & $6.4 \pm 0.1^{\mathrm{a}, \mathrm{b}, \mathrm{c}}$ \\
\hline 1-penten-3-ol & 7.16 & $5.1 \pm 0.1$ & $5.8 \pm 0.1$ & $5.3 \pm 0.2^{a, c}$ & $5.8 \pm 0.01^{b, d}$ & $5.6 \pm 0.4^{a, c}$ \\
\hline cyclopentanol & 7.51 & nd & $5.8 \pm 0.2^{b, d}$ & $5.4 \pm 0.1^{\mathrm{a}, \mathrm{c}, \mathrm{d}}$ & $6 \pm 0.2^{b, d}$ & $\mathrm{nd}^{\mathrm{b}, \mathrm{c}}$ \\
\hline 4-pentenol & 10.3 & $6.1 \pm 0.0$ & $5.8 \pm 0.3$ & $5.9 \pm 0.2$ & $6.2 \pm 0.0$ & $6.1 \pm 0.1$ \\
\hline $\begin{array}{l}\text { 3-methyl-1- } \\
\text { butanol }\end{array}$ & 8.53 & nd & $\mathrm{nd}^{\mathrm{b}, \mathrm{c}, \mathrm{d}}$ & $6.7 \pm 0.0^{\mathrm{a}, \mathrm{c}, \mathrm{d}}$ & $7.2 \pm 0.0^{\mathrm{a}, \mathrm{b}, \mathrm{d}}$ & $\mathrm{nd}^{\mathrm{b}, \mathrm{c}}$ \\
\hline $\begin{array}{l}\text { 4-methyl-3- } \\
\text { cholro 2- } \\
\text { pentanol } \\
\text { aldehydes }\end{array}$ & 10.03 & nd & $\mathrm{nd}^{\mathrm{b}, \mathrm{c}, \mathrm{d}}$ & $\mathrm{nd}^{\mathrm{c}}$ & $5.3 \pm 0.3^{a, b, d}$ & $\mathrm{nd}^{\mathrm{c}}$ \\
\hline $\begin{array}{l}\text { 3-methyl-1- } \\
\text { butanal }\end{array}$ & 6.44 & nd & $5.8 \pm 0.0^{c}$ & $6.5 \pm 0.7^{c}$ & $7 \pm 0.0^{\mathrm{a}, \mathrm{b}, \mathrm{d}}$ & $6 \pm 0.2^{c}$ \\
\hline $\begin{array}{l}\text { 2-methyl-1- } \\
\text { butanal }\end{array}$ & 6.66 & nd & $5.6 \pm \underset{b, c, d}{0} 0.0$ & $6.3 \pm 0.0^{\mathrm{a}, \mathrm{c}, \mathrm{d}}$ & $6.7 \pm 0.0^{\mathrm{a}, \mathrm{b}, \mathrm{d}}$ & $n d^{a, b, c}$ \\
\hline heptanal & 7.52 & nd & $n d^{b, c, d}$ & $\mathrm{nd}^{\mathrm{d}}$ & $\mathrm{nd}^{\mathrm{d}}$ & $5.9 \pm 0.3^{a, b, c}$ \\
\hline pentanal & 7.59 & $5 \pm 0.0$ & $5.1 \pm 0.0$ & $5.3 \pm 0.2$ & $5.1 \pm 0.0$ & $4.9 \pm 0.0$ \\
\hline $\begin{array}{c}\text { hydrocarbons } \\
\text { benzene }\end{array}$ & 6.54 & $6.4 \pm 0.2$ & $5.5 \underset{b, c, d}{ \pm} 0.2$ & $6.1 \pm 0.8^{a, c}$ & $6.5 \pm 0.8^{\mathrm{a}, \mathrm{b}, \mathrm{d}}$ & $6.2 \pm 1.2^{\mathrm{a}, \mathrm{c}}$ \\
\hline $\begin{array}{l}\text { 3,3-dimethyl- } \\
\text { hexane }\end{array}$ & 9.04 & $6.1 \pm 0.1$ & $6.7 \pm 0.1$ & $6.8 \pm 0.1$ & $6.8 \pm 0.1$ & $6.8 \pm 0.2$ \\
\hline $\begin{array}{l}\text { 4-methyl- } \\
\text { heptane }\end{array}$ & 9.13 & nd & $5.8 \pm 0.2$ & $5.7 \pm 0.1$ & $6 \pm 0.1$ & $5.9 \pm 0.1$ \\
\hline $\begin{array}{l}\text { 2,3,4-trimethyl- } \\
\text { pentane }\end{array}$ & 8.86 & $5.8 \pm 0.1$ & $6.3 \pm 0.1$ & $6.5 \pm 0.7$ & $6.5 \pm 0.1$ & $6.5 \pm 0.0$ \\
\hline $\begin{array}{l}\text { 3,3-dimethyl- } \\
\text { octane }\end{array}$ & 12.55 & nd & $4.8 \pm 0.1$ & $4.8 \pm 0.1$ & $5 \pm 0.0$ & $4.9 \pm 0.2$ \\
\hline $\begin{array}{l}\text { 2,2,5-trimethyl- } \\
\text { hexane }\end{array}$ & 9.71 & nd & $4.7 \pm 0.1$ & $4.8 \pm 0.1$ & $4.8 \pm 0.0$ & $4.9 \pm 0.1$ \\
\hline $\begin{array}{l}2,2,4 \text { trimethyl } \\
\text { heptane }\end{array}$ & 12.14 & nd & $5 \pm 0.1$ & $5.1 \pm 0.1$ & $5.2 \pm 0.0$ & $5.5 \pm 0.1$ \\
\hline
\end{tabular}

nd: not detected

${ }^{a}$ indicates statistically significant difference of mean compared to control at day 14.

${ }^{\mathrm{b}}$ indicates statistically significant difference of mean compared to L. piscium at day 14.

${ }^{\mathrm{C}}$ indicates statistically significant difference of mean compared to $B$. thermosphacta at day 14. ${ }^{d}$ indicates statistically significant difference of mean compared to mixed culture at day 14. 
Table 3 : Free amino acids content $(\mathrm{mg} / \mathrm{kg})$ in all batches of tropical cooked peeled shrimp stored at $8^{\circ} \mathrm{C}$ after 1 day and 14 days . Values are averages of three analysis \pm standard deviation

\begin{tabular}{|c|c|c|c|c|c|}
\hline \multirow{2}{*}{ Amino acid } & Day1 & \multicolumn{4}{|l|}{ Day 14} \\
\hline & Control & Control & L. piscium & $B t$ & 80 \\
\hline Taurine & $189.7 \pm 0.6$ & $186.7 \pm 1.5^{\mathrm{C}}$ & $189.3 \pm 2.1^{\mathrm{C}}$ & $194.7 \pm 5.7^{\mathrm{a}, \mathrm{b}, \mathrm{d}}$ & $187 \pm 4.3^{\mathrm{C}}$ \\
\hline Aspartic acid & $19.3 \pm 1.1$ & $19.3 \pm 0.6^{c}$ & $20.3 \pm 1.5^{c}$ & $25.3 \pm 1.5^{\mathrm{a}, \mathrm{b}, \mathrm{d}}$ & $19.7 \pm 1.5^{c}$ \\
\hline Threonine & $83.7 \pm 7.2$ & $70.7 \pm 23^{d}$ & $82.3 \pm 5^{d}$ & $89 \pm 9.2^{d}$ & $94.7 \pm 1.5^{\mathrm{a}, \mathrm{b}, \mathrm{c}}$ \\
\hline Serine & $101.7 \pm 5.7$ & $98.7 \pm 7.6^{d}$ & $101.7 \pm 3.1^{d}$ & $93 \pm 5.3^{d}$ & $104.7 \pm 0.6^{a, b, c}$ \\
\hline Asparagine & $175.7 \pm 6.6$ & $170 \pm 13.1$ & $168 \pm 9$ & $158 \pm 7$ & $173.3 \pm 6.4$ \\
\hline Glutamic acid & $290.7 \pm 16.6$ & $288.7 \pm 7.1^{b, c, d}$ & $\underset{\mathrm{a}, \mathrm{c}, \mathrm{d}}{314 \pm 14.1}$ & $\underset{a, b, d}{341.7 \pm 13.6}$ & $335.7 \pm 9.1^{\mathrm{a}, \mathrm{b}, \mathrm{c}}$ \\
\hline Glutamine & $627.3 \pm 15.5$ & $581.7 \pm 57$ & $527 \pm 43.7$ & $566.4 \pm 30.6$ & $541.3 \pm 23.8$ \\
\hline Proline & $3178 \pm 252.7$ & $3147.3 \pm 88.5^{c}$ & $3294 \pm 144^{c}$ & $3431 \pm 129.5$ & $3351.7 \pm 53.1^{\circ}$ \\
\hline Glycine & $2575 \pm 64.5$ & $2461.3 \pm 56.3$ & $\underset{c, d}{2501 \pm 17.1}$ & $2583 \pm 21.3^{a, b, d}$ & $\underset{a, b, c}{2552.3 \pm 47.7}$ \\
\hline Alanine & $860 \pm 39$ & $843.7 \pm 22.3^{c}$ & $814 \pm 26.2^{c}$ & $\underset{a, b, d}{888.3 \pm 61.5}$ & $844.33 \pm 24.5^{c}$ \\
\hline Valine & $148.3 \pm 8.5$ & $144 \pm 11.1$ & $141 \pm 8.5$ & $147 \pm 6.2$ & $143.7 \pm 2.5$ \\
\hline Isoleucine & $81.7 \pm 5.1$ & $80.3 \pm 4.9^{c}$ & $74.3 \pm 6^{c}$ & $69 \pm 4.3^{\mathrm{a}, \mathrm{b}, \mathrm{d}}$ & $73.7 \pm 0.6^{c}$ \\
\hline Leucine & $158 \pm 7.9$ & $150.3 \pm 5.7$ & $148 \pm 8.5$ & $144.3 \pm 7.6$ & $150.7 \pm 1.1$ \\
\hline Tyrosine & $134.3 \pm 9.4$ & $130.6 \pm 11.6$ & $125.7 \pm 9.7$ & $136 \pm 9.2$ & $131.3 \pm 6.5$ \\
\hline Phenylalanine & $87.3 \pm 5.5$ & $87 \pm 6$ & $83.3 \pm 3.8$ & $86 \pm 3.6$ & $83.7 \pm 2.1$ \\
\hline Histidine & $132.7 \pm 10.5$ & $130 \pm 12.1^{c}$ & $129.7 \pm 5.1^{\mathrm{c}}$ & $149.3 \pm 1.1^{a, b, d}$ & $168 \pm 6^{c}$ \\
\hline Ornithine & $29.7 \pm 2.1$ & $30.7 \pm 2.1$ & $29.7 \pm 3.8$ & $32.3 \pm 3.2$ & $33 \pm 1$ \\
\hline Lysine & $290.7 \pm 16.8$ & $272.7 \pm 33.1$ & $253 \pm 14.8$ & $279.7 \pm 21$ & $271.7 \pm 23$ \\
\hline Arginine & $3149.3 \pm 132.5$ & $3042 \pm 65.5^{b, c, d}$ & $3240.3 \pm 82$ & $3259.4 \pm \underset{a}{ } \pm 139.6$ & $3283.3 \pm 98^{a}$ \\
\hline
\end{tabular}

${ }^{a}$ indicates statistically significant difference of mean compared to control at day 14.

${ }^{\mathrm{b}}$ indicates statistically significant difference of mean compared to $L$. piscium at day 14 .

${ }^{\mathrm{c}}$ indicates statistically significant difference of mean compared to $B$. thermosphacta at day 14.

${ }^{d}$ indicates statistically significant difference of mean compared to mixed culture at day 14 . 


\section{Figures}

Figure 1: Growth of Lactococcus piscium CNCM I-4031 and Brochothrix thermosphacta CD340 in peeled and cooked shrimp packed under modified atmosphere and stored at $8^{\circ} \mathrm{C}$. (घ) L. piscium alone; - L. piscium in co-inoculation; $(x) B$. thermosphacta alone; ( $\mathbf{\Delta}) B$. thermosphacta in co-inoculation. Values are averages of three analyses \pm standard deviation.

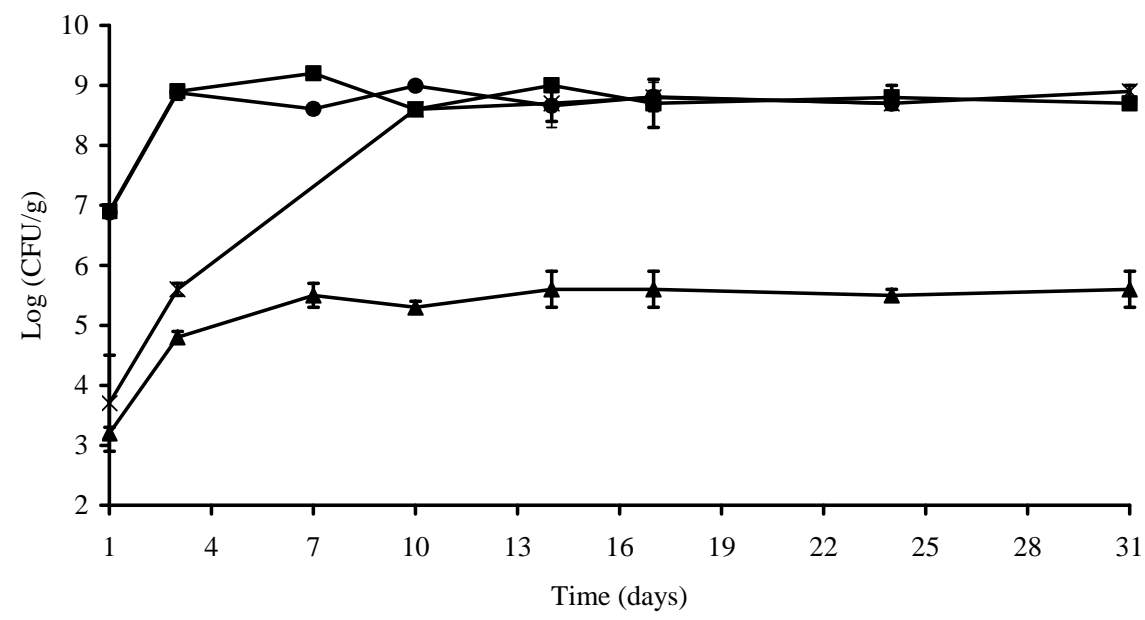

Figure 2: TTGE fingerprints of the amplified V3 region of $16 \mathrm{~S}$ rRNA gene of total bacterial DNA extracted from cooked peeled shrimp at different times during storage at $8^{\circ} \mathrm{C}$ : (a) day 1 ,( b) day 7 and ( c) day 14. Lane 1: marker profile (the arrow indicates $B$. thermosphacta band); lane 2: L. piscium marker; lanes 3-4: sterility control; lanes 5-6: L. piscium batch; lanes 7-8: B. thermosphacta batch; lanes 9-10: mixed culture.

a

b

C

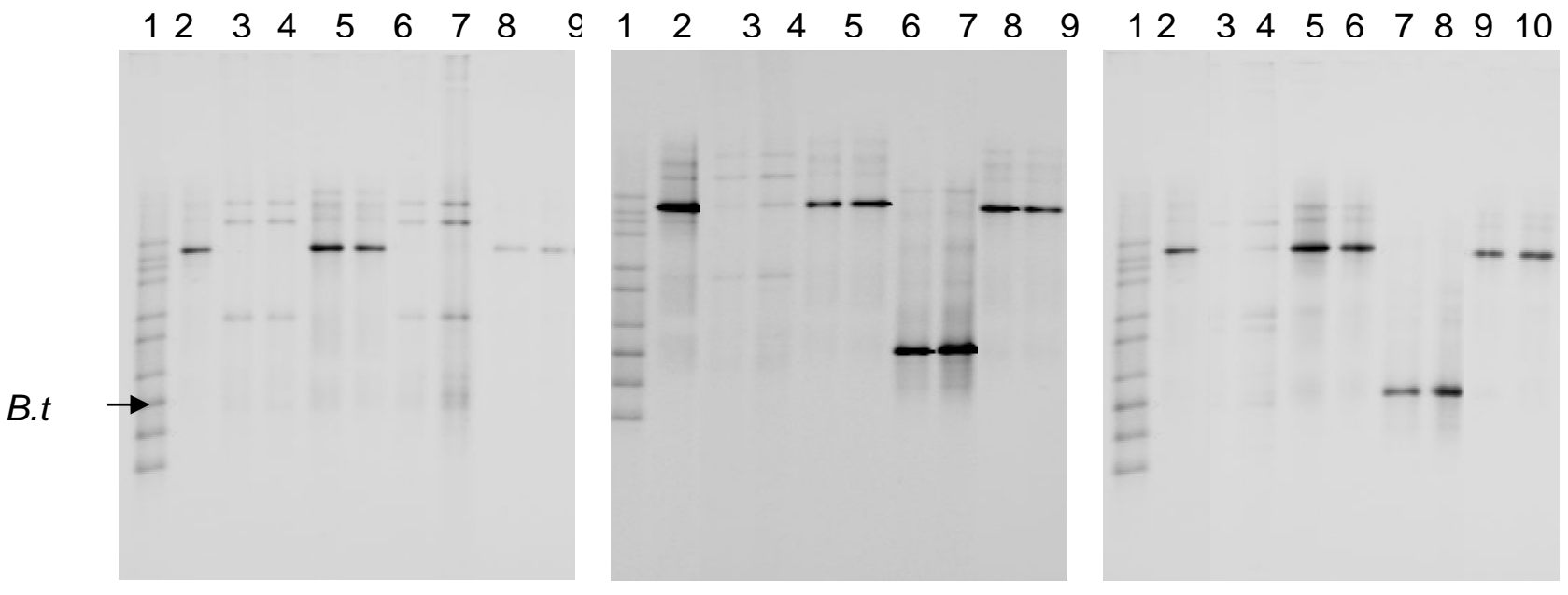


Figure 3: Representation of the evolution of odours of cooked peeled shrimp samples stored at $8^{\circ} \mathrm{C}$ on plane $1-2$ of principal component analysis. Lx: L. piscium CNCM I-4031 at day x; $\mathrm{Bx}$ :. B. thermosphacta at day $\mathrm{x}$; LBx, co-inoculated with $L$. piscium and $B$. thermosphacta at day $x$.

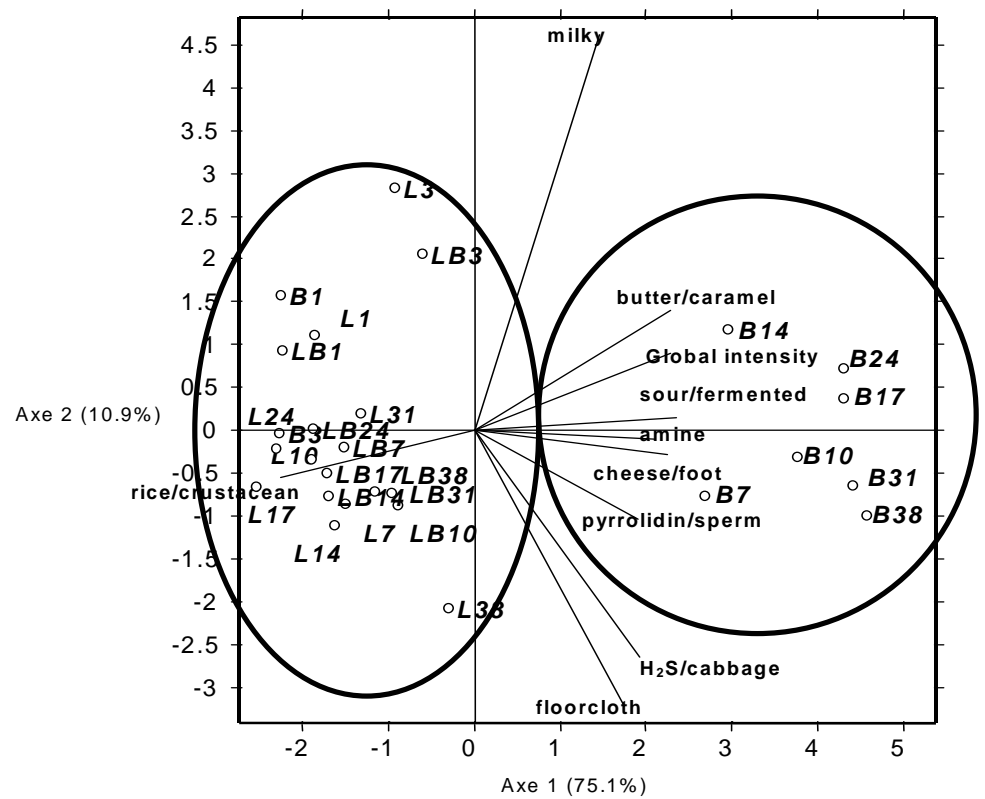

Figure 4: Quality coefficient of inoculated cooked peeled MAP shrimp stored at $8^{\circ} \mathrm{C}$. ( $\left.\mathbf{\square}\right)$ scores of batches inoculated with L. piscium CNCM I-4031 alone; ( $\mathrm{x}$ ) B. thermosphacta CD340 alone; $(\boldsymbol{\Delta})$ L. piscium and B. thermosphacta. Values are averages of 36 analyses \pm standard deviation. Scores higher than 3 are judged as unacceptable.

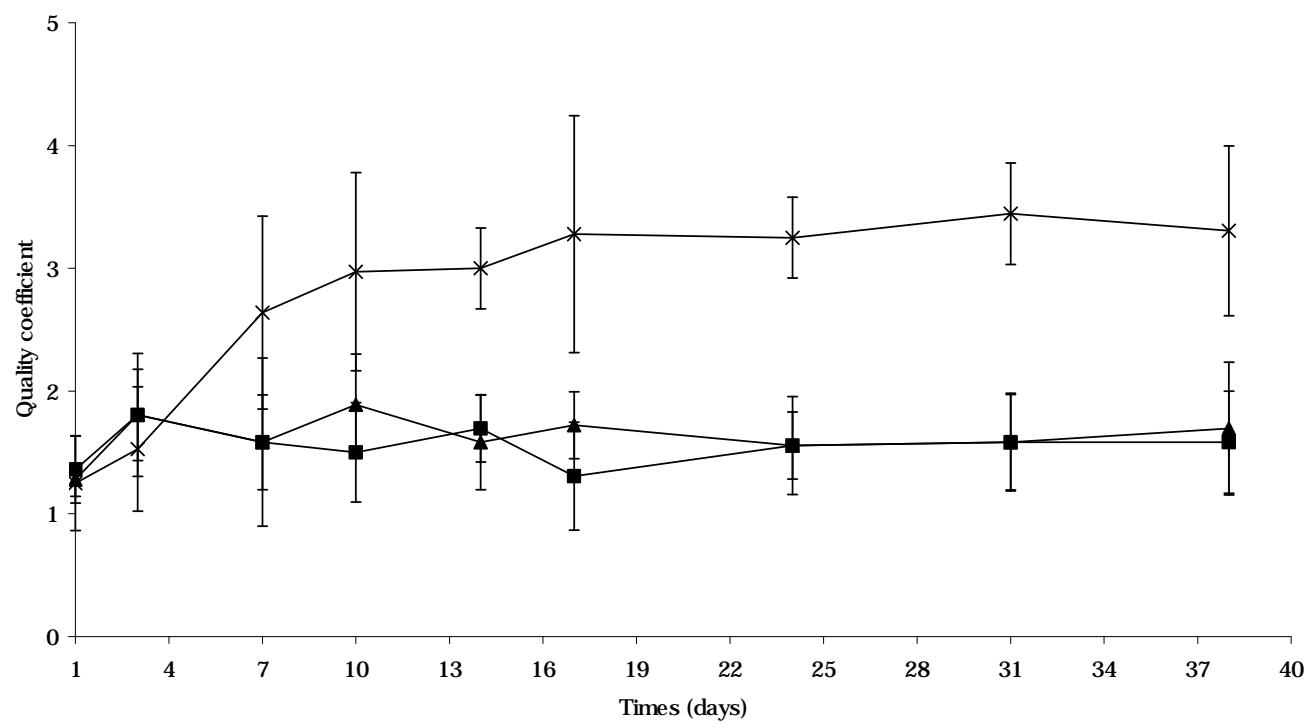


Figure 5: L-lactic acid (dotted line) and $\mathrm{pH}$ (solid line) evolution in peeled and cooked shrimp packed under modified atmosphere and stored at $8^{\circ} \mathrm{C}$. (-) non inoculated; ( $\left.\boldsymbol{(}\right)$ inoculated with L. piscium CNCM I-4031 alone; (x) B. thermosphacta CD340 alone; ( $\mathbf{\Delta}$ ) co-inoculated with $L$. piscium and $B$. thermosphacta. Values are averages of three analyses \pm standard deviation.

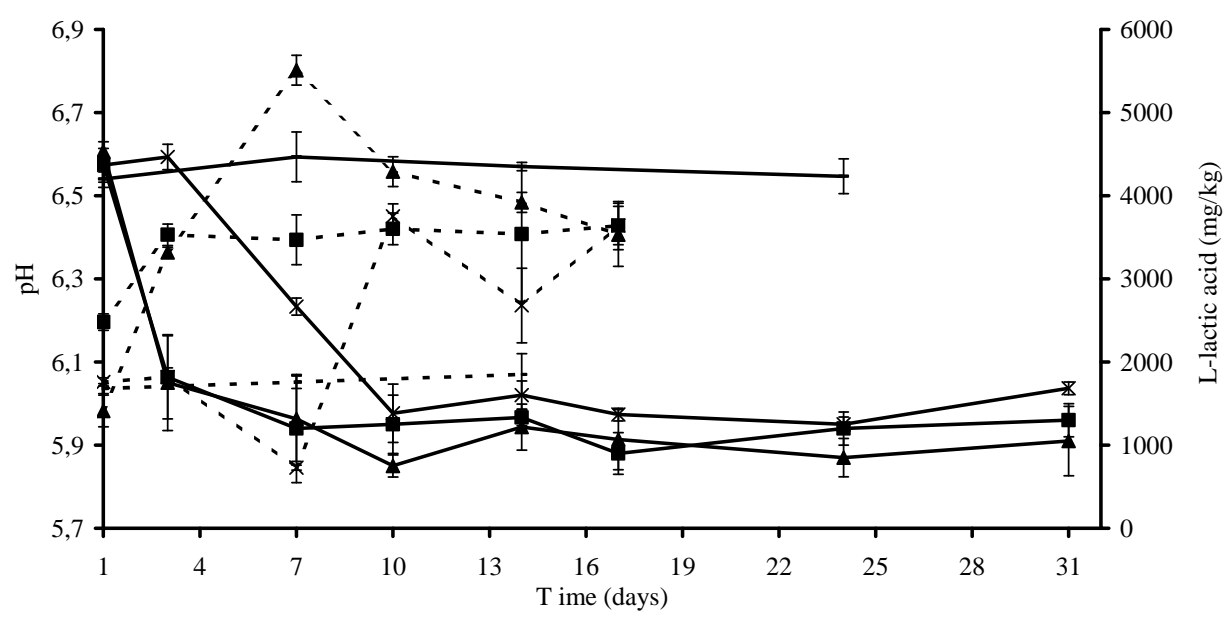

